مقآ مِّوهشى

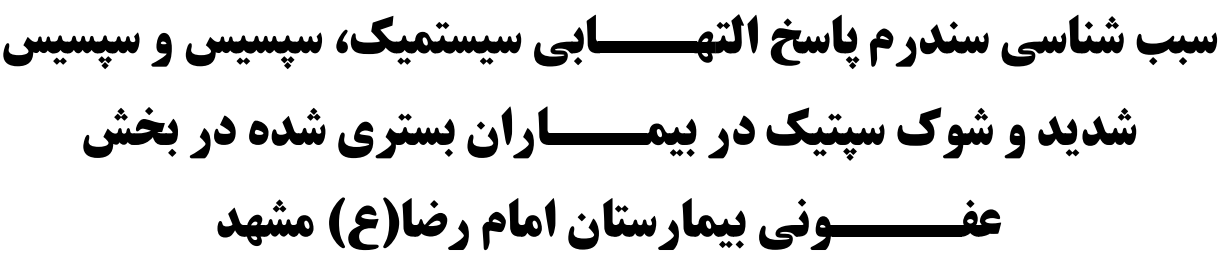

مجيد غفورى '"، على اكبر حيدرى '، حلنوش قوشجى

'متخصص بيماريهاى عفونى، استاديار دانشكاه علوم يزشكى خراسان شمالى، بجنورد، ايران

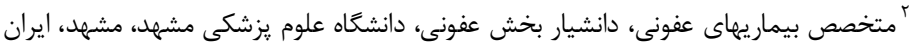

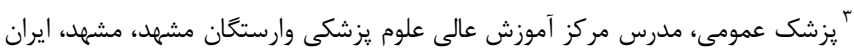

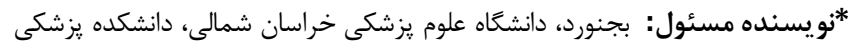

يست الكترونيك: Ghafourim841@yahoo.com

وصول:|rq1/9/V:

جكيده

زمينه و هدف: سندرم باسخ التهابى سيستميك (SIRS) با حضور دو مورد از تب يا هيبوترمى، تاكى پنه، تاكى كاردى و لكوسيتوز يا

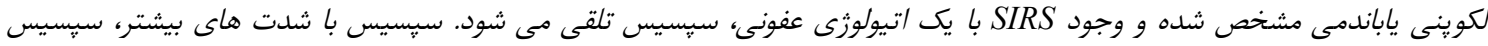

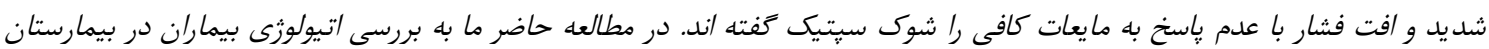
امام رضا مشهلدمى بردازيم.

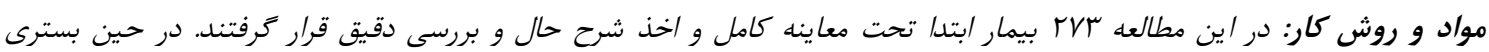

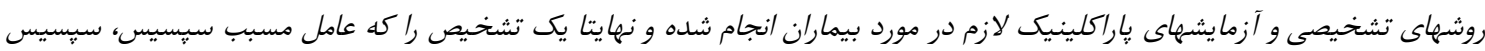
شديد و SIRS بود در برسشنامه قرار داديم.

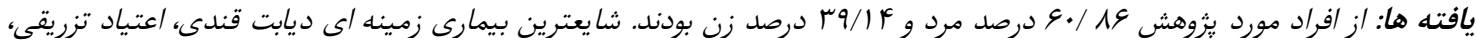

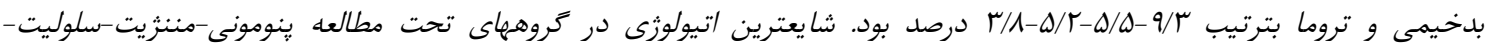

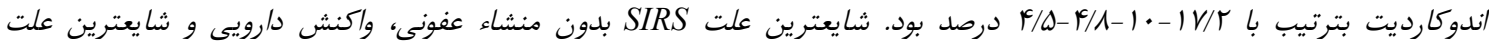

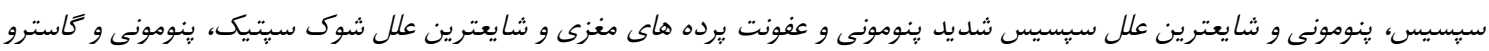

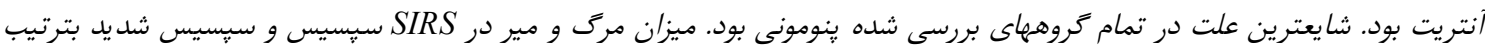

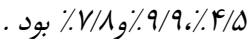

نتيجه كيرى: بر اساس مطالعه حاضر ما نتيجه كرفتيه كه در بخش عفونى در زمان مطالعه شا يعترين علت سيسيس ينومونى و شايعترين

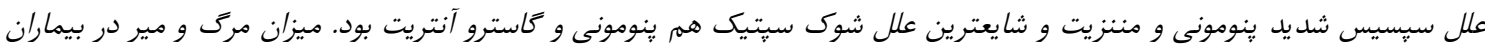

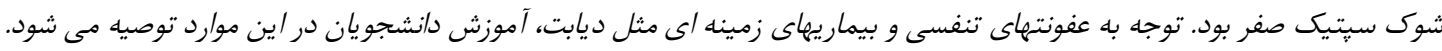

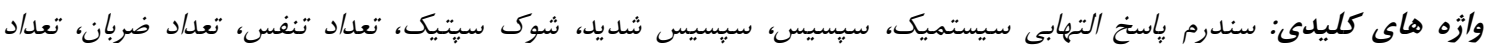

خلاصه به آن 'SIRS مى گويند. وقتى SIRS در يك كلبولهاى سفيد خون

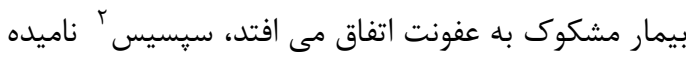

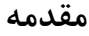
سيسيس، سيسيس شديد و شوك سيتيك براى توصيف

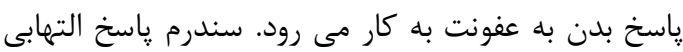

1 -Systemic Inflammatory Response Syndrome 2 -Sepsis سيستميك در واقع קاسخ سيستميك بدن است كه به به صورت تب، تاكيكاردى و لكوسيتوز بروز كرده و به طور 
و علائم حياتى و فاكتورهاى دخيل در SIRS ثبت شد.

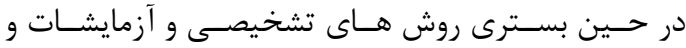

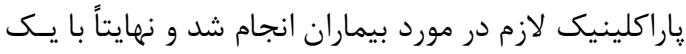

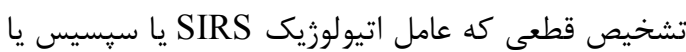

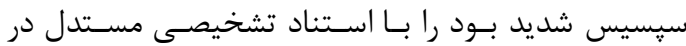
يرسشنامه هايى كه از ابتداى بسـترى در يرونـده بيمـاران

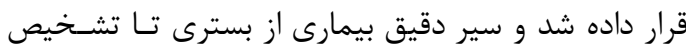
نهايى" بسته به ميزان مورد لزوم جهت درمـان اسـتاندارد

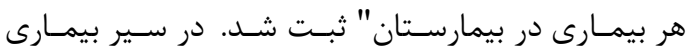

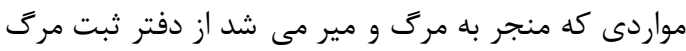
و مير بخش عفونى ثبت مى شد. حجم نمونه با توجه به ا طلاعات اوليه كه نشان مى دهـد تقريبا •و درصد بيماران بسترى شده داراى منشـاء SIRS

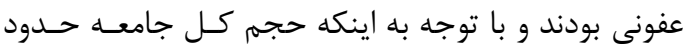

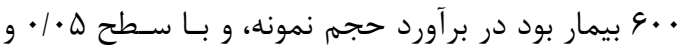

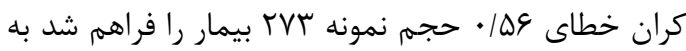

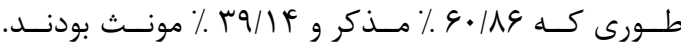

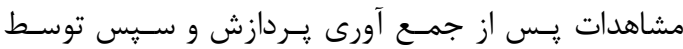

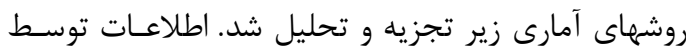

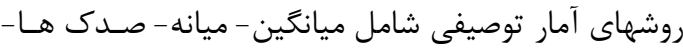
جداول فراوانى و تــوافقى و نمودارهـاى آمـارى و شـاخص هاى تمايل مركزى و يراكنـدگى توصـيف شـد. مشــاهدات

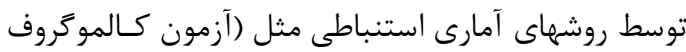

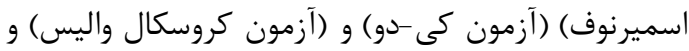

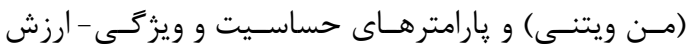

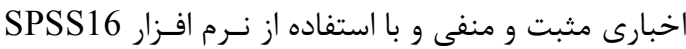
تجزيه و آناليز شده اند.

يافته ها

ز · · ب بيمار مورد مطالعه در صد فراوانى SIRS، سيسيس، سيسيس شديد و و شوك سيتيك بترتيب r|

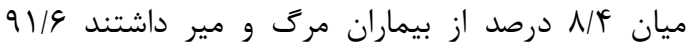
درصد بهبودى داشتند (جدول r). از بين بيماران مورد بررسى سيسيس و 9N/9 درصد سيسيس شديد تبدار بودند و بقيه
مى شود. اگر افت فشار خون پاسخ دهنده به مايعات يا

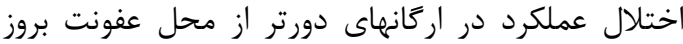
كند، سيسيس شديد و در صورتيكه اسيدوز لاكتيك يا اختلال خون رسانى اندامهاى حياتى بدن و يا افت فشار

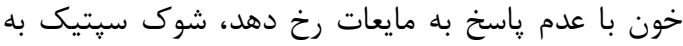
وجود مى آيد [1].

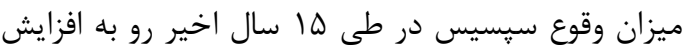
مى باشد. نكته كليدى در درمان سيسيس، شناسايى دريى زودرس و شروع درمان بر اساس علايم، پييش از بروز عوارضى جون كاهش فشارخون مى باشد. سندرم پاسخ التهابى سيستميك (SIRS) در اوايل دهـ

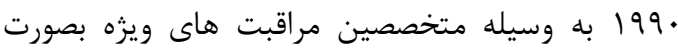

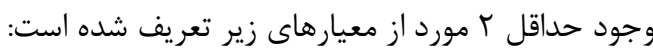

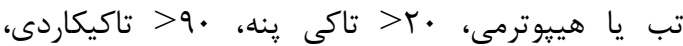

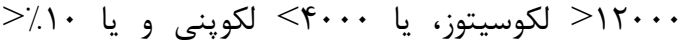
باندمى [r] ممكن است داراى علت عفونى يا غير عفونى باشد. SIRS در صورتى كه علت عفونى وجود داشته باشد اصطلاحا

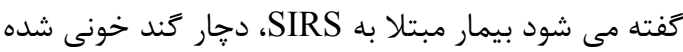

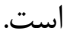

ميزان بروز سيسيس شديد و شوك سيتيك در طى • سال كذشته رو به افزايش است و تعداد موارد آن در سال

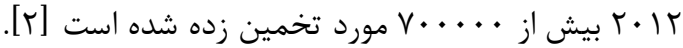

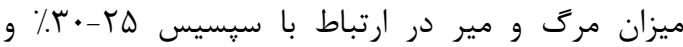

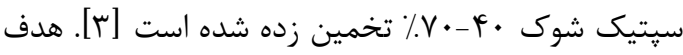

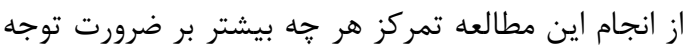
به سيسيس و علل مرگ و مير و مديريت صحيح اين

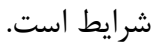

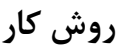
اين مطالعه از نوع بررسى بيماران بوده و كليه بيمارانى كه از قسمت اسكرنينگ بيمارستان از تيرماه لهم لغايت تيرماه براه

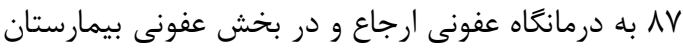

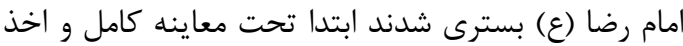
شرح حال و بررسى دقيق قرار گرفتند و كليه مشخصات فردى و خانوادگى و سوابق بيمار و بيمارى فرد تعيين شده 


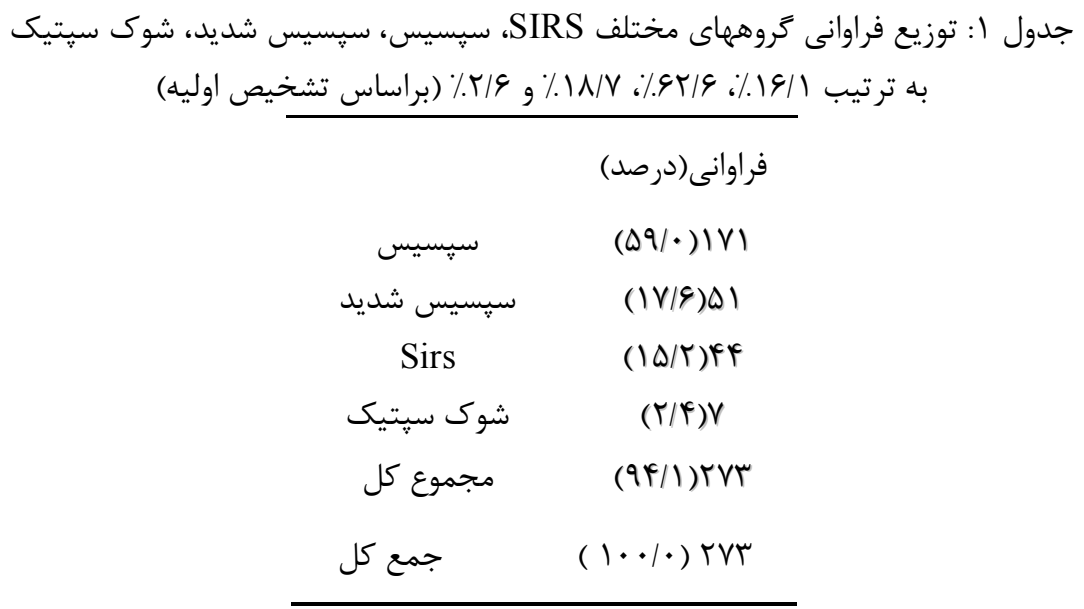

جدول r: فراوانى و درصد مرگ ومير در زروه هاى مختلف

\begin{tabular}{|c|c|c|c|c|}
\hline & & فوت نشده & فوت شده & مجموع \\
\hline & تعداد & et & r & FF \\
\hline \multirow[t]{3}{*}{ SIRS } & درصد گروههاى مختلف & $\% .90 / 0$ & $\% \varphi / \Delta$ & $\% 1 \cdots$ \\
\hline & مرى و مير & $\% 19 / 1$ & $\%$. $/ \mathrm{V}$ & $\% 19 / 1$ \\
\hline & 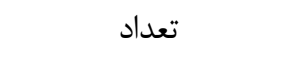 & $\mid \Delta F$ & IV & $|V|$ \\
\hline \multirow[t]{3}{*}{ سيسيس } & درصد گروههاى مختلف & $\% .9 \cdot 11$ & $\% .9 / 9$ & $\% 1 \cdots$ \\
\hline & مرگ و مير & $\% .91 / 9$ & $\%$ \% $/ 9$ & $\%$. $/ 9$ \\
\hline & 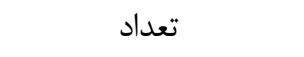 & iv & q & $\Delta l$ \\
\hline \multirow[t]{3}{*}{ سِيسيس شديد } & درصد گروههاى مختلف & $\% 9 r / r$ & $\% \mathrm{~V} / \Lambda$ & $\% 1 \cdots$ \\
\hline & مرگ و مير & $\% / 1 / 1$ & $\% \mathrm{IV} / \mathrm{T}$ & $\%) \wedge / V$ \\
\hline & 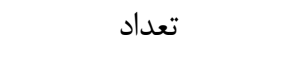 & V & • & V \\
\hline \multirow[t]{3}{*}{ شوك سيتيك } & درصد گروههاى مختلف & $\% 1 \ldots$ & $\% \cdot$ & $\% 1 \cdots$ \\
\hline & مرَى و مير & $\% / \Lambda / \Lambda$ & $\% \cdot$ & $\% / \% / 9$ \\
\hline & 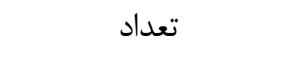 & $r \Delta \cdot$ & r & r T \\
\hline \multirow[t]{2}{*}{ مجموع } & درصد گروههاى مختلف & $\% .91 / 9$ & $\% / \mathcal{F}$ & $\% 1 \cdots$ \\
\hline & مرگ و مير & $\% 1 \ldots$ & $\% 1 \ldots$ & $\% 1 \ldots$ \\
\hline
\end{tabular}




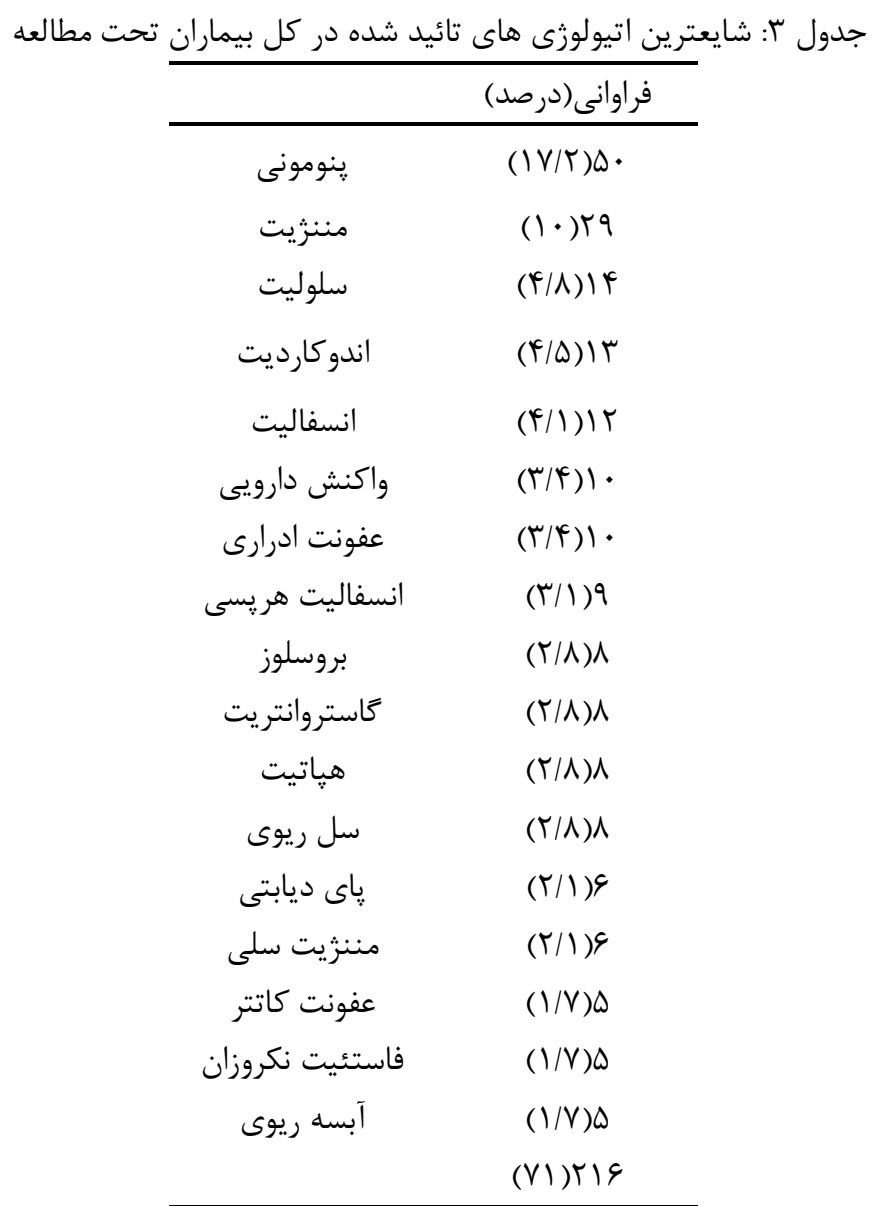

ethiolog1

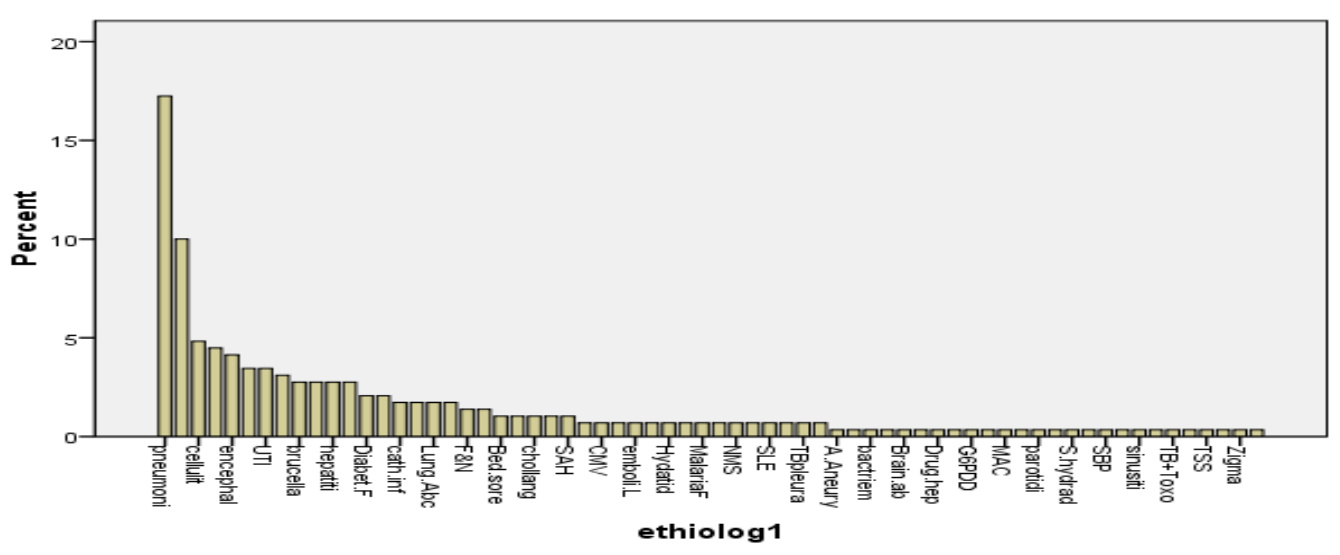

نمودار |: هيستو 


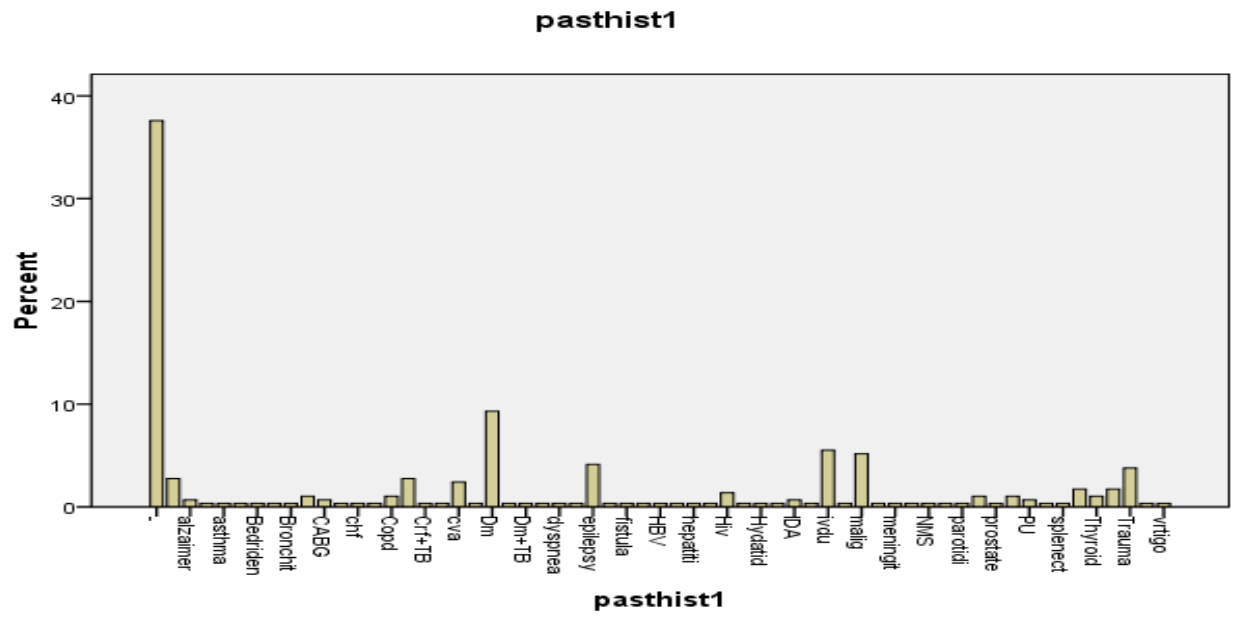

نمودار r: شايعترين بيماريهاى زمينه اى بررسى شده در گروه مطالعه

مطالعه اى از زاين وجود SIRS دربيماران اى سى يو راد داد داد

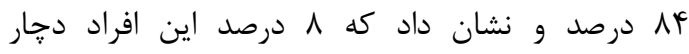

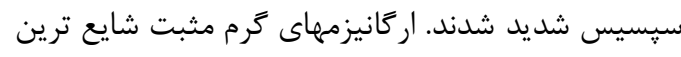

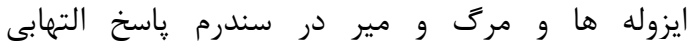

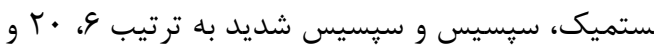

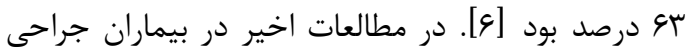
هم ثابت شده كه شدت SIRS وسيله اى مفيد در درد

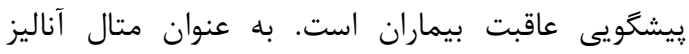

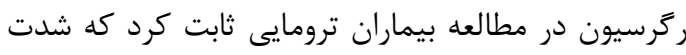

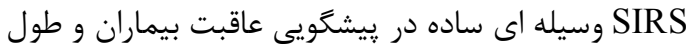

$$
\text { مدت بسترى آنان است. }
$$
در مطالعه اى ديكر توسط دكتر حيدرى در بخت انش عفونى

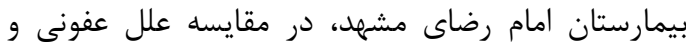

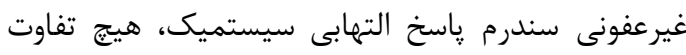

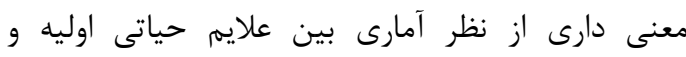

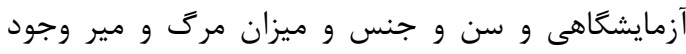

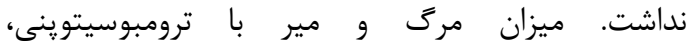

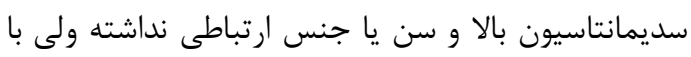
كاهش فشارخون، لكوسيتوز شديد و شدت سندرم التهني التهابى

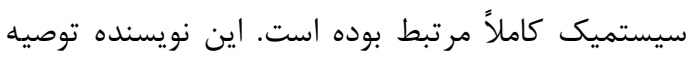
مى كند با توجه به اين كه شدت اين بيمارى ارتباط
موارد تب نداشتند. ميزان اتيولوزى عفونى و غير عفونى در

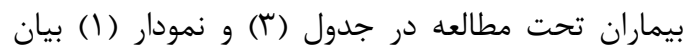

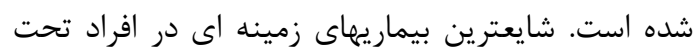

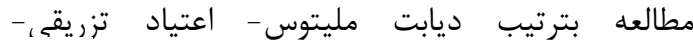
ماليخنانسى و تروما بوده است كه درصد هر كر كدام

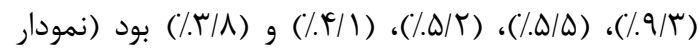
.$(r$

ميانگين سن، تعداد تنفس، تعداد ضربان قلب، معيار

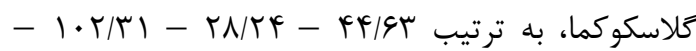
تقريباً سا 1 بود. بحث

ميزان وقوع كَند خونى شديد و شوك سيتيك در طى بـ

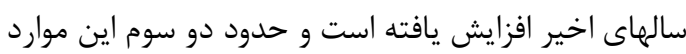

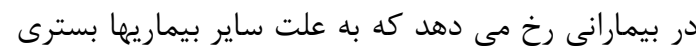

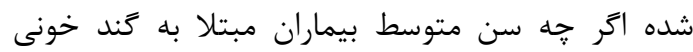

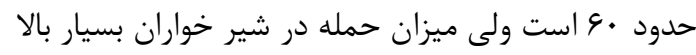

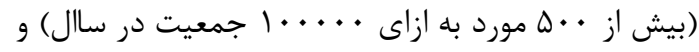

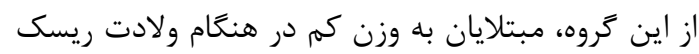
بيشترى دارند [ماء]. 


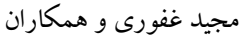

$$
\begin{aligned}
& \text { شايعترين علت SIRS به تنهايى بدون منشا عفونى. } \\
& \text { سيسيس، سيسيس شديد و شوك سيتيك به ترتيب } \\
& \text { واكنش دارويى ينومونى و مننزيت، ينومونى، ينومونى و }
\end{aligned}
$$

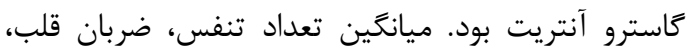

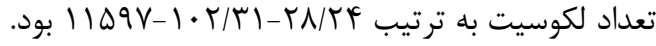

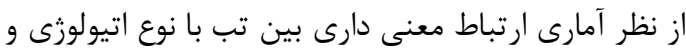

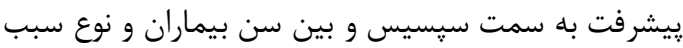

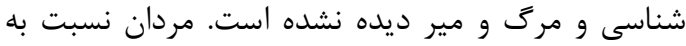

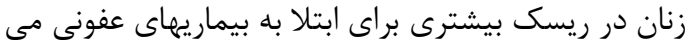

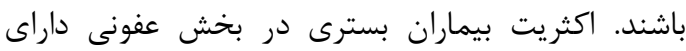

$$
\begin{aligned}
& \text { ريسك فاكتور و شايعترين ان ديابت و اعتياد تزريقى است. } \\
& \text { در مطالعه ما مرك ومير در بيماران شوك سيتيك صفر دئ دئر }
\end{aligned}
$$

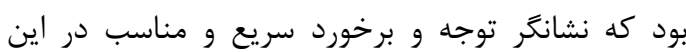

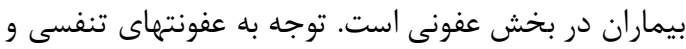

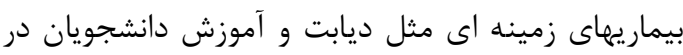

$$
\begin{aligned}
& \text { اين موارد توصيه مى شود. }
\end{aligned}
$$

\section{References}

1. Munford RS, Suffredini AF,Sepsis, In: Mandell GL, Bennett JE, Dolin R, "et al", Principles and practice of infectious disease. 7th ed. Philadelphia: Elsevier 2010; Vol.2. P. 987-1010.

2. Munford RS, Severe sepsis and septic shock, In: Kasper DL, Loscalzo J, Fauci AS, et al. Harrison's principles of internal medicine. 18th ed. New York: McGraw-Hill; 2012;Vol 2. P. 2223-31.

3. Russell JA, Management of sepsis, N Engl J Med 2006 Oct; 355(16): 1699-1713.

4. American College of Chest Physicians Society of Critical Care Medicine Consensus Conference Committee, Definitions for sepsis and organ failure and guidelines for the use of innovative therapies in sepsis, Crit Care Med 1992; 20:864-874.
واضحى با ميزان مركى و مير دارد، توجه بيثترى بـ ثبت

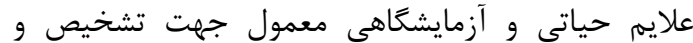

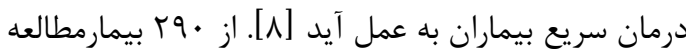
حاضر كه با احتمال يك عفونت بسترى بودند و در مطالعه بـ بدان

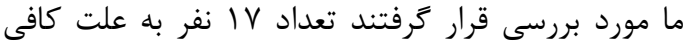

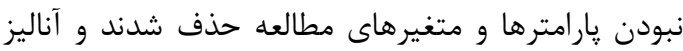

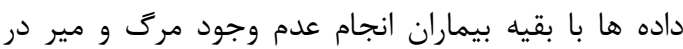
موارد سيتيك شوك در بخش عفونى نمايانكر توجه

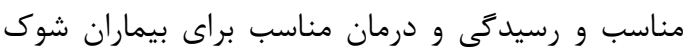

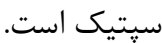
توجه به بيماريهاى زمينه اي در بيماران بسترى در بخش

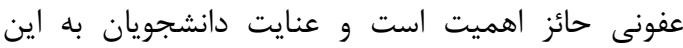

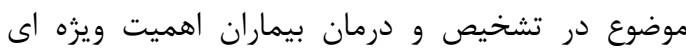

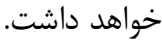
نتيجه كيرى بر اساس مطالعه حاضر ما نتيجه گرفتئيم كه درى بخش عفونى در زمان مطالعه در اين مطالعه، 5. Watson RS, Carcillo JA, Linde-Zwirble WT, "et al", The epidemiology of severe sepsis in children in the United States, Am J Respir Crit Care Med 2003;167:695-701

6. Shibata K, Funada H, The epidemiology of SIRS, Sepsis in Japan Nippon Rinsho 2004; 62(12):2184-8.

7. Napolitano LM, Ferrer T, McCarter RJ Jr, Scalea TM, J Systemic inflammatory response syndrome score at admission independently predicts mortality and length of stay in trauma patients Trauma 2000; 49(4):647-52; discussion 652-3.

8. Heydari AA, Ghaboli MJ, The relationship between Severity of the systemic Inflammatory Response Syndrome (SIRS) and Its Etiology and Outcome, Med J Mashhad Univ Med Sci 2007; 50(97): 321-326[Persian] 
Original Article

\title{
Etiology of SIRS, Sepsis, Severe Sepsis and Septic shock in hospitalized patients of infection department of Imam Reza Hospital
}

\author{
Ghafouri $M^{l} *$, Heydari $A A^{2}$, Ghoushchi $G^{3}$ \\ ${ }^{1}$ Assistant Professor of Infectious Disease, North Khorasan University of Medical Sciences, Bojnurd, Iran. \\ ${ }^{2}$ Associate Professor of Infectious Disease, Mashhad University of Medical Sciences, Mashhad, Iran. \\ ${ }^{3}$ General Physician, Varastegan Medical educating center, Mashhad, Iran.
}

*Corresponding Author: Dean of Faculty of Medicine, North Khorasan University of Medical Sciences, Bojnurd, Iran.

Email:

Ghafourim841@yahoo.com
Abstract

Background \& Objective: Systemic inflammatory response syndrome (SIRS) is defined with two of the following items: Fever or hypothermia, tachypnea, tachycardia and leukocytosis or leukopenia or bandemia. Sepsis is SIRS with an infectious etiology. Severe sepsis is sepsis plus associated hypoxemia and insufficiency of tissue perfusion or hypotension. Septic shock is severe sepsis without response to adequate fluid therapy. In this article we study abovementioned parameters.

Materials \& Methods: The first physical Exam, presentation, past history and familial history were determined. Vital sign and SIRS factors, Diagnosis interventions and paraclinical labs and final diagnosis were recorded. The cause of SIRS, sepsis, severe sepsis was enrolled in the questionnaire with close monitoring and observation from admission till final diagnosis.

Results: In Admitted patients $60.86 \%$ were male and $39.14 \%$ were female median respiratory rate, pulse rate, white blood cell was 28.24, 102.31 and 11597 respectively. Diabetes mellitus 9.3\%, Intravenous drug abuse, (5.5\%), malignancy (5.2\%), and trauma (3.8\%) were the most important predisposing disease. The most frequent etiology was pneumonia $17.2 \%$, meningitis $10 \%$, cellulitis $4.8 \%$ and endocarditis $4.5 \%$. The most frequent etiology of SIRS without infection was drug reaction, and the most frequent cause of sepsis, severe sepsis and septic shock were pneumonia and meningitis pneumonia, pneumonia and gastroenteritis respectively. There was no significant relation between age and type of etiology and mortality. Rate of Mortality in sepsis and severe sepsis were $4.5 \%-9.9 \%-7.8 \%$ respectively.

Conclusion: According to the results of this study the most frequent etiology of sepsis, severe sepsis and septic shock were pneumonia, meningitis, pneumonia, pneumonia and gastroenteritis respectively. The rate of mortality in septic shock patients was zero. We recommend attention to respiratory infections and predisposing disease like diabetes and training and education of students

Keywords: SIRS - Sepsis - Severe Sepsis - Septic Shock - Pulse RateRespiratory Rate - White Blood Cell.

Submitted:8 Sep 2012

Revised:20 Oct 2012

Accepted:27 Nov 2012 